Kelola

\title{
EVALUASI PENCAPAIAN STANDAR PELAYANAN MINIMAL BERDASARKAN PRINSIP GOOD GOVERNANCE DI SEKOLAH DASAR NEGERI ${ }^{1}$
}

\author{
Novita Wijanarti \\ Alumni Program Pascasarjana Magister Manajemen Pendidikan \\ FKIP-Universitas Kristen Satya Wacana \\ novita.wija@gmail.com
}

\begin{abstract}
This study aimed to evaluate the achievement of Minimum Service Standards according to Minister of Education and Culture Act, Number 23/2013 based on the principles of Good Governance in SD Negeri 4 Kaliaman Jepara through discrepancy evaluation model. This study was evaluation research consisted of the definition phase, the instalation, process, and product. This research subject was the principal, teachers and students of six grade. Data source was obtained from 12 teachers including Principal and 35 students through interviews, questionnaires, and study of documents. Data collection techniques used were interviews, questionnaires, and observations. Data processing techniques performed by data classification, data presentation, and data verification. The data validity used triangulation of data. The results of this study indicated that the definition phase of the school had a vision in line with the objective of Minimum Service Standards program, supported by adequate human resources in terms of number of educators and educational qualifications as well as the infrastructure that supported understanding of the principles of Good Governance. In addition, the installation phase, had been carried out by looking at the expectations and activities that made the School Work Plan and saw the challenges facing schools with the implementation of the principles of Good Governance which was held on the activities of each type of service in the Minimum Service Standards. At the process phase, School Work Plan was already implemented based on the principles of Good Governance Implementation. At the product phase, it was seen from the Minimum Service Standards data achievement and implementation of the principles of good governance were equally obtained good category. The Minimum Service Standards attainment of the six types of services was $87.4 \%$, gained good criteria $(B)$ and the implementation of the principle of good governance to the implementation was $87.5 \%$ with good criteria $(B)$. The program is still feasible to proceed because the Minimum Service Standards program that has been made reached and acquired good categories.
\end{abstract}

Keywords: Minimum Service Standards, Good Governance Principles, Peblic Elementary Shool.

\footnotetext{
${ }^{1}$ Versi lain naskah ini pernah dipresentasikan dalam Seminar Nasional ALFA yang diselenggarakan oleh Universitas Achmad Dahlan, Yogyakarta pada tanggal 20-03-2016.
} 


\section{PENDAHULUAN}

Pendidikan merupakan sebuah instrumen dan agenda penting dalam pembangunan di negara Indonesia. Mengingat peran penting pendidikan, maka selayaknya pendidikan dijadikan prioritas utama dalam pembangunan baik tingkat pusat, provinsi maupun daerah. Anggaran pendidikan 20\% dari APBN bagi kelangsungan proses pendidikan formal maupun non formal di Indonesia dari Pemerintah sangat bermanfaat bagi pendidikan. Melalui anggaran tersebut diharapkan mampu memperbaiki kualitas pendidikan. Menyadari akan pentingnya kualitas pendidikan, Pemerintah berupaya dalam memenuhi hak setiap warga negara untuk meningkatkan kualitas hidup bangsa Indonesia. Hal tersebut seperti yang tertuang dalam Undang-undang Dasar Republik Indonesia tahun 1945 yang mewajibkan pemerintah untuk bertanggung jawab dalam mencerdaskan kehidupan bangsa dan menciptakan kesejahteraan umum.

Rendahnya mutu dan kualitas pendidikan merupakan permasalahan yang ada pada pendidikan dasar. Hal ini dapat diketahui dari hasil prestasi siswa atau tingkat penguasaan siswa terhadap materi pelajaran yang tergolong rendah. Prestasi belajar siswa sebagai salah satu indikator rendahnya kualitas pendidikan. Rendahnya kualitas pendidikan dipengaruhi oleh berbagai komponen. Mulyana (2009: 93) komponen- komponen tersebut antara lain:

“1) siswa; 2) guru sebagai tenaga pendidik; 3) administrasi; 4) kurikulum; 5) keuangan; 6) sarana dan prasarana sebagai instrumental". Komponen tersebut sangat berpengaruh pada mutu dan kualitas pendidikan.

Berdasarkan pendapat tersebut di atas, minat baca siswa merupakan hal yang mempengaruhi kualitas pendidikan. Siswa di Indonesia memiliki minat baca yang sangat rendah. Banyak orang tua yang tidak memperhatikan anaknya karena kesibukan bahkan jarang memfasilitasi anak dengan buku-buku bacaan karena tidak memiliki waktu untuk membelikan buku atau karena keadaan ekonomi sehingga Indonesia jauh tertinggal dari negara lain. Dengan memiliki minat membaca, siswa akan mengetahui segala ilmu pengetahuan karena manusia belajar dimulai dari membaca.

Selain itu, Sumber Daya Manusia yaitu pendidik yang berkualitas juga merupakan hal penting dalam pendidikan meliputi jumlah guru yang memadai dan kualifikasi guru sesuai dengan kompetensi yang ditetapkan secara nasional. Dengan rendahnya kualitas guru akan berakibat terhadap rendahnya pelayanan publik sektor pendidikan karena guru merupakan kunci suksesnya pendidikan. Banyak guru lama yang sudah mengajar selama puluhan tahun 
bahkan akan pensiun sering tidak disiplin melaksanakan tanggungjawabnya seperti tidak selalu menyusun rencana proses pembelajaran. Hal ini sesuai dengan pendapat Idrus (2009:166) "oleh karena itu masih banyak guru lama yang belum berkualitas tinggi baik dalam pengetahuan maupun dalam proses pembelajaran”. Dengan rendahnya kualitas guru maka kualitas guru harus ditingkatkan. Menurut Nur (2009:6) peningkatan kualitas guru menurut model UNESCO adalah "Kondisi kerja para guru, seperti besarnya kelas, jumlah jam, fasilitas pendukung diperhatikan."

Kurikulum juga berpengaruh terhadap kualitas pendidikan. Dengan adanya perubahan kurikulum berkali-kali yang memiliki unsur politik seperti jual beli buku antara penerbit dengan siswa menjadi suatu alasan demi perbaikan mutu pendidikan. Faktanya dapat dilihat dari siswa yang memiliki saudara selisih satu atau dua tahun tidak dapat mempergunakan buku tersebut karena adanya pergantian kurikulum.

Sarana pendidikan juga ada yang masih dalam keadaan tidak layak untuk dipergunakan. Sekolah diharapkan mampu menyediakan sarana dan prasaranan bagi siswa. Berdasarkan Peraturan Pemerintah No. 19 tahun 2005 pasal 42 ayat 1 dan 2 tentang standar sarana dan prasarana pendidikan bahwa setiap satuan pendidikan wajib memiliki sarana prasarana yang diperlukan untuk menunjang proses pendidikan. Prasarana pendidikan merupakan macam-macam peralatan, benda-benda yang digunakan guru dan siswa untuk memudahkan dan membuat nyaman penyelenggaraan pendidikan. Prasarana pendidikan seperti ruang kelas, meja, kursi, alat peraga, globe, dan buku-buku pelajaran. Semakin lengkap sarana dan prasarana pendidikan maka akan semakin efektif pula proses belajar mengajar yang dilaksanakan sehingga siswa akan semakin mudah menyerap setiap materi yang diajarkan.

Dengan adanya desentralisasi diharapkan setiap sekolah memiliki tanggungjawab untuk berkembang secara optimal dan mandiri untuk meningkatkan kualitas pendidikan di sekolahnya masing-masing dipengaruhi oleh berbagai komponen seperti siswa, guru, kurikulum, sarana prasarana dan lain-lain yang sangat menunjang kualitas pendidikan. Hal ini seperti pendapat Amtu (2011:83) menyatakan "desentralisasi juga bisa membuat layanan lebih bertanggung jawab kepada masyarakat lokal yang mengeluhkan suatu layanan". Melalui kebijakan desentralisasi tersebut dengan adanya pemberian otonomi pendidikan yang luas pada sekolah yang merupakan upaya peningkatan mutu pendidikan oleh pemerintah.

Pendidikan telah mendapat perhatian dari pemerintah hal ini terbukti dengan adanya pelayanan pada pendidikan dasar yang telah ditetapkan Pemerintah yang disebut Standar 
Pelayanan Minimal yang merupakan tolok ukur kinerja pelayanan pendidikan yang diselenggarakan oleh Kabupaten /Kota dan oleh satuan pendidikan sesuai Peraturan Menteri Pendidikan dan Kebudayaan Nomor 23 tahun 2013 tentang Standar Pelayanan Minimal Pendidikan Dasar di Kabupaten/Kota.

Dengan adanya pelaksanaan kebijakan SPM diharapkan SPM diprioritaskan agar mampu meningkatkan kesejahteraan rakyat sebagai cerminan negara yang sejahtera berdasarkan paradigma Good Governance. "SPM harus diprioritaskan karena didisain sebagai suatu instrumen untuk memenuhi SNP secara bertahap (Dikdas Bantul, 2014)". Maka, implementasi SNP perlu dilaksanakan secara bertahap karena membutuhkan sumberdaya yang sangat besar, kapasitas SDM serta kapasitas kelembagaan yang sangat tinggi.

Penelitian sebelumnya yang digunakan untuk data pendukung salah satunya penelitian yang dilakukan oleh Khoirina Nuryani tahun 2014 dengan judul "Evaluasi Pelaksanaan SPM Pendidikan Dasar SD Unggulan Muhammadiyah Kretek Kabupaten Bantul Tahun Ajaran 2013/2014". Penelitian ini bertujuan untuk mengetaui pelaksanaan dan kendala Standar Pelayanan Minimal. Hasil yang diperoleh, pelaksanaan SPM indikator pencapaian yang telah memenuhi SPM sebesar 72,42\% dan belum memenuhi SPM sebesar 27,58\%. SPM belum terpenuhi dalam hal ketersediaan peraga IPA, penerapan RPP, pelaksanaan supervisi oleh kepala sekolah dan RKS. Kendala yang dihadapi dalam pelaksanaan SPM yaitu kurangnya informasi yang diterima sekolah mengenai SPM, keterbatasan anggaran untuk pengadaan sarana dan prasarana khususnya peraga IPA, kualitas SDM baik guru maupun kepala sekolah masih kurang dan kurangnya efektivitas pelaksanaan program sekolah.

Pelaksanaan Standar Pelayanan Minimal masih mengalami banyak kendala, penelititian Khoirina Nuryani diperkuat oleh berita pada Kompas mengenai pelaksanaan Standar Pelayanan Minimal di Jawa Tengah sebagai berikut:

"Pelaksanaan SPM sesuai amanat Permendikbud No 23/2013 masih mengalami kendala baik di pemerintah daerah maupun kota yang diberi kewajiban untuk melaksanakan peraturan itu belum mampu memenuhinya. Padahal SPM merupakan salah satu syarat yang dibutuhkan dalam rangka mewujudkan pendidikan bermutu". (suara merdeka.com)

Perhatian dari Pemerintah perlu diberikan apresiasi, tetapi pada kondisi nyata masih ada indikator yang belum sesuai dengan SPM yang di harapkan oleh Pemerintah 
Pelaksanaan SPM adalah syarat menuju pendidikan bermutu tetapi pada kenyataannya SPM belum bisa terwujud secara maksimal karena mengalami berbagai kendala.

Dari pemaparan permasalahan tersebut mengenai pelaksanaan SPM maka penulis mengkaji melalui penelitan mengenai Evaluasi Pencapaian Standar Pelayanan Minimal di SD Negeri 4 Kaliaman Jepara berdasarkan prinsip Good Governance.

\section{METODE PENELITIAN}

Rancangan yang diterapkan pada penelitian ini adalah penelitian evaluasi. Metode yang digunakan yaitu evaluasi discrepancy dengan empat tahap yaitu definisi (desain), instalasi (kelengkapan), proses, dan produk.

Subjek penelitian meliputi Kepala sekolah beserta guru kelas maupun guru mata pelajaran berjumlah 12 guru serta siswa kelas VI berjumlah 35 siswa SDN 4 Kaliaman Jepara. Sumber data yang digunakan peneliti melalui wawancara, studi dokumentasi, dan kuesioner. Teknik pengumpulan data yang digunakan melalui wawancara kepada Kepala Sekolah serta guru, pengamatan langsung mengenai sarana dan prasarana, dan kuesioner mengenai prinsip Good Governance untuk mengetahui respon siswa yang menerima pelayanan SPM. Setelah data terkumpul maka ada pengolahan data yang dilakukan dengan penggolongan data, penyajian data, dan verifikasi. Selain itu, untuk menguji keabsahan data pada penelitian ini digunakan triangulasi data yang meliputi triangulasi sumber dan triangulasi teknik. menggunakan triangulasi data yang meliputi triangulasi sumber dan triangulasi teknik. Indikator keberhasilan dalam penelitian ini adalah penccapaian Standar Pelayanan Minimal SDN 4 Kaliaman menunjukkan kriteria baik karena pelaksanaan prinsip Good Governance juga memperoreh kriteria baik.

\section{HASIL PENELITIAN}

Berdasarkan hasil penelitian, berikut merupakan hasil penelitian pencapaian Standar Pelayanan Minimal berdasarkan prinsip Good Governance di SD negeri 4 Kaliaman Jepara. Hasil evaluasi SPM melalui empat tahap yaitu definisi (desain), instalasi, proses dan produk. Tahap definisi yaitu perumusan tujuan, aktivitas serta pengalokasian sumber daya sebagai standar yang ditentukan untuk masing-masing komponen. Pada tahap pertama dilakukan dengan mengetahui visi sekolah, sarana dan prasarana, siswa, jumlah pendidik dan tenaga kependidikan serta status kepegawaian, yang dilakukan melalui wawancara dan studi dokumentasi. Selain itu standar yang dipakai untuk diperbandingkan dengan rancangan 
dalam program yaitu standar berdasarkan Permendikbud Nomor 23 tahun 2013. Tahap instalasi merupakan standar baku untuk diperbandingkan dengan penilaian awal program pada RKS sekolah dari profil, harapan, dan tantangan yang masuk pada indikator SPM dilakukan dengan studi dokumentasi dapat dilihat pada tabel 1.1 di bawah ini. Pada tahap proses dengan adanya pengumpulan data dari keterlaksanaan program dengan tujuan untuk memperhatikan kemajuan kemudian menentukan program apa saja yang sudah terlaksana sesuai dengan harapan, tahap ini dilakukan dengan wawancara dan studi dokumentasi.

Tabel 1.1 Hasil Kuesioner Siswa Mengenai Prinsip Good Governance

\begin{tabular}{|c|c|c|c|c|c|c|}
\hline No & $\begin{array}{l}\text { Pertanyaan } \\
\end{array}$ & SS & $\mathbf{S}$ & $\mathbf{R R}$ & TS & STS \\
\hline 1. & $\begin{array}{l}\text { Sekolah cepat dalam wujudkan pemenuhan sarana prasaran seperti buku } \\
\text { teks, pengayaan, referensi, dan alat peraga yang dibutuhkan siswa. }\end{array}$ & 28 & 6 & 1 & & \\
\hline \multicolumn{7}{|c|}{ Prinsip Daya Tanggap } \\
\hline 2. & $\begin{array}{l}\text { Guru selalu datang tepat waktu dan pulang sesuai waktu yang } \\
\text { ditentukan. }\end{array}$ & 35 & & & & \\
\hline \multicolumn{7}{|c|}{ Prinsip Efisien dan Efektif } \\
\hline 3. & $\begin{array}{l}\text { Guru memberikan les atau jam tambahan kepada siswa sebelum } \\
\text { melaksanakan UN/US. }\end{array}$ & 35 & & & & \\
\hline \multicolumn{7}{|c|}{ Prinsip Partisipasi } \\
\hline 4. & Kurikulum di sekolah ini sudah sesuai dengan ketentuan Pemerintah. & 35 & & & & \\
\hline \multicolumn{7}{|c|}{ Prinsip Penegakan Hukum } \\
\hline 5. & $\begin{array}{l}\text { Guru menguasai materi pelajaran yang disampaikan dengan kreatif dan } \\
\text { tidak membosankan. }\end{array}$ & & 24 & 10 & 1 & \\
\hline \multicolumn{7}{|c|}{ Prinsip Profesionalisme } \\
\hline 6. & $\begin{array}{l}\text { Guru selalu memberikan ulangan, tes kepada siswa dan menilai siswa } \\
\text { sesuai dengan kemampuannya. }\end{array}$ & 8 & 20 & 7 & & \\
\hline \multicolumn{7}{|c|}{ Prinsip Transparan } \\
\hline 7. & $\begin{array}{l}\text { Kepala sekolah selalu menilai dan memantau guru saat mengajar di kelas } \\
\text { dua kali dalam satu semester. }\end{array}$ & & & & & 35 \\
\hline \multicolumn{7}{|c|}{ Prinsip Pengawasan } \\
\hline 8. & Guru membagikan rapor kepada semua siswa dan orangtua siswa. & 35 & & & & \\
\hline \multicolumn{7}{|c|}{ Prinsip Akuntabilitas } \\
\hline 9. & $\begin{array}{l}\text { Kepala sekolah memberitahukan hasil Ujian Akhir Semester, Ujian } \\
\text { Nasional, dan Ujian Kenaikan Kelas kepada semua siswa dan orangtua } \\
\text { siswa. }\end{array}$ & 34 & 1 & & & \\
\hline \multicolumn{7}{|c|}{ Prinsip Kesetaraan } \\
\hline 10. & Komite sekolah terlibat penuh dalam kegiatan di sekolah. & 35 & & & & \\
\hline
\end{tabular}

Sumber: diolah pada 11 Oktober 2015 melalui kuesioner

Pada tahap produk dilakukan dengan pengumpulan data dan analisis penentuan tingkat pencapaian sasaran. Dalam tahap ini dapat dilihat apakah harapan program sesuai dengan tujuan akhir program dengan membandingkan kinerja dengan standar serta mengetahui kendala serta mencari solusi. Data pencapaian SPM dapat dilihat dari gambar 1.1 
dan pelaksanaan prinsip Good Governance pada SPM dilihat pada gambar 1.2. melalui prinsip daya tanggap, efisien dan efektif, partisipasi, penegakan hukum, profesionalisme, transparan, pengawasan, akuntabilitas, kesetaraan, wawasan ke depan.

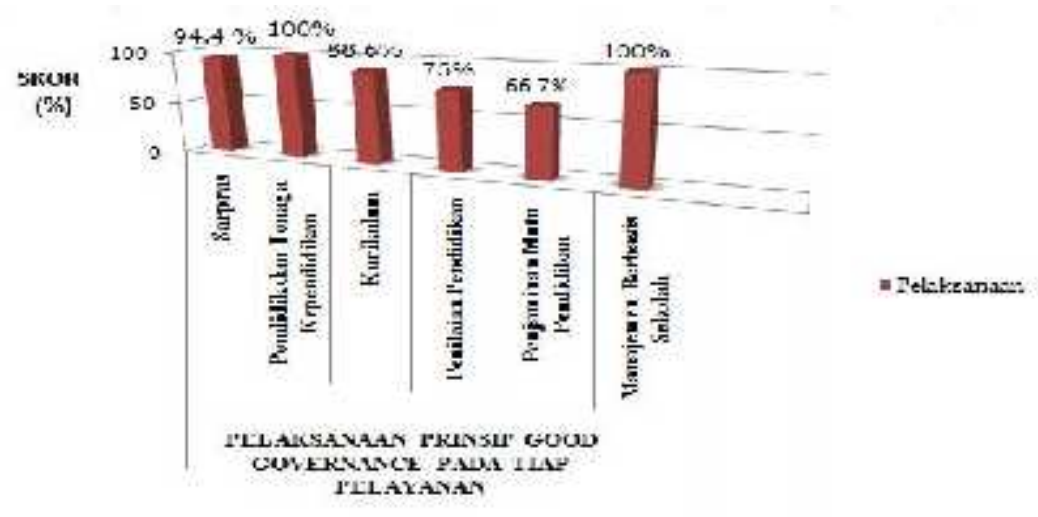

Gambar 1.1 Pelaksanaan Prinsip Good Governance Pada Tiap Pelayanan Sumber: Hasil data pengolahan 9 Oktober 2015

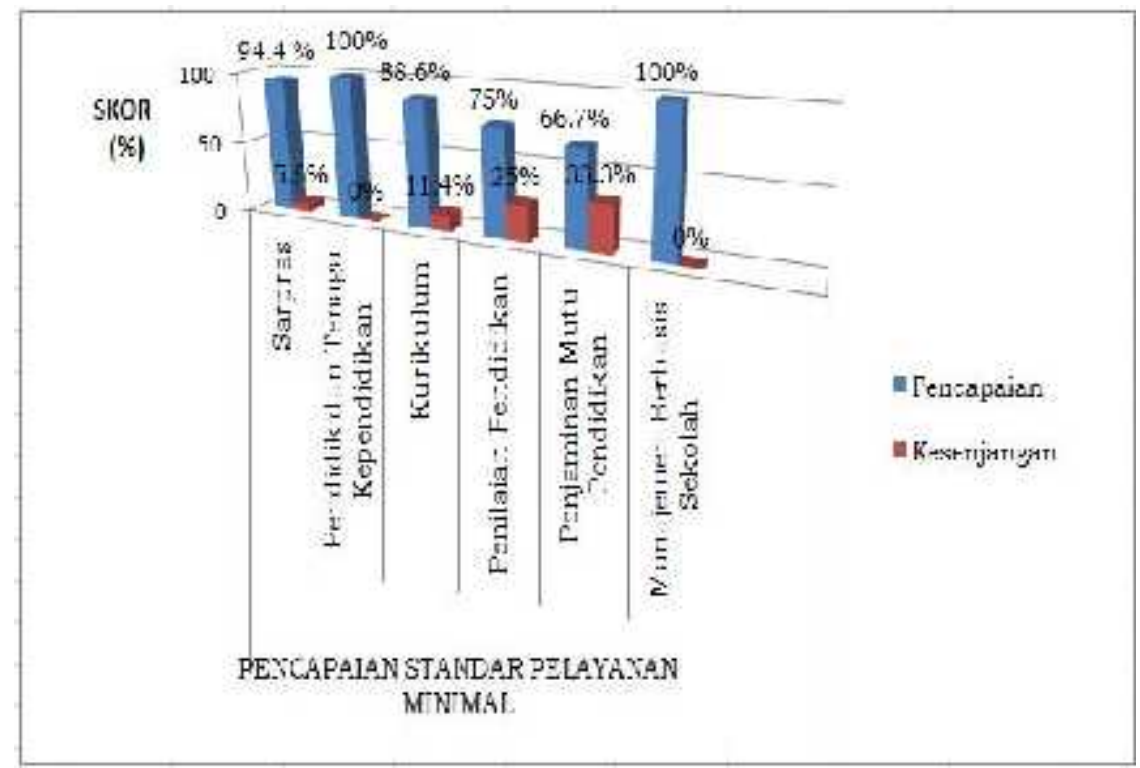

Gambar 1.2 Hasil Pencapaian Standar Pelayanan Minimal Secara Keseluruhan Sumber: Hasil data pengolahan 8 Oktober 2015

Berdasarkan penelitian skor secara keseluruhan pada pencapaian SPM jenis pelayanan sarana dan prasarana 94,4\% dengan kriteria baik (B) dengan kesenjangan 5,6\% dan skor pada pelaksanaan prinsip Good Governance pada SPM jenis pelayanan sarana dan prasarana 94,2 
\% memperoleh kriteria baik (B). Pada pelayanan sarana dan prasarana masih terkendala oleh dana. Masukan bagi sekolah adalah semua stakeholder harus memiliki daya tanggap yang tinggi terhadap sarana dan prasarana sekolah, serta membuat sebuah skala prioritas pelayanan mana yang paling dibutuhkan oleh peserta didik yang harus diprioritaskan.

Pencapaian SPM jenis pelayanan pendidik dan tenaga kependidikan 100\% dengan kriteria sangat baik (AB) dan kesenjangan 0\% serta pelaksanaan prinsip Good Governance pada SPM jenis pelayanan tenaga pendidik dan kependidikan 100\% memperoleh kriteria sangat baik $(\mathrm{AB})$.

Selanjutnya pencapaian SPM jenis pelayanan kurikulum 88,6\% mendapatkan kriteria baik (B) dan kesenjangan 33,4\% serta prinsip Good Governance pada SPM jenis pelayanan kurikulum dengan skor pelaksanaan mencapai 88, 8\% dengan kriteria baik (B). Kendala yang muncul pada Standar Pelayanan Minimal jenis pelayanan kurikulum adalah guru SDN 4 Kaliaman belum profesional dalam penerapan RPP dikarenakan masih ada kesenjangan dilihat dari data bahwa semua guru tidak selalu menyusun RPP berdasarkan silabus. Supaya Standar Pelayanan Minimal dapat terpenuhi secara maksimal pada jenis pelayanan kurikulum pada indikator penerapan RPP, solusinya adalah Kepala Sekolah harus meningkatkan kompetensinya melaksanakan kewajiban untuk melakukan supervisi supaya guru terpantau dalam penyusunan Perencanaan Proses Pembelajaran sesuai silabus.

Selain itu, pencapaian SPM jenis pelayanan penilaian pendidikan dengan skor $75 \%$ memperoleh kriteria baik (B) dengan kesenjangan 25\% serta pelaksanaan prinsip Good Governance pada SPM jenis pelayanan penilaian pendidikan dengan skor 75,7\% memperoleh kriteria baik (B). Kendala berdasarkan jenis pelayanan penilaian guru, guru SDN 4 Kaliaman belum transparansi secara maksimal karena tidak selalu melaksanakan penilaian mengacu pada SK dan KD, sesuai rencana, penilaian untuk meningkatkan kemampuan belajar siswa. Solusinya guru harus meningkatkan kompetensi pedagogik agar menjadi pendidik yang lebih profesional untuk meningkatkan mutu dan kualitas pendidikan.

Pencapaian SPM jenis pelayanan penjaminan mutu pendidikan memperoleh pencapaian 66,7 \% dengan kriteria baik (B) dengan kesenjangan 33,3\% dan pelaksanaan prinsip Good Governance pada SPM jenis pelayanan penilaian pendidikan dengan skor 66,4 $\%$ dengan kriteria baik (B). Kendala yang dihadapi pada jenis pelayanan penjaminam mutu pendidikan yaitu Kepala Sekolah belum melakukan supervisi secara berkala. Solusi untuk kendala mengenai supervisi, Kepala Sekolah harus melakukan supervisi dan meningkatkan kompetensinya agar permasalahan yang dihadapi pendidik dalam proses pengajaran dapat 
diketahui kepala sekolah serta dapat dicari solusinya sehingga mutu pendidikan menjadi semakin lebih baik lagi.

Pencapaian SPM pada jenis layanan Manajemen Berbasis Sekolah dengan tingkat pencapaian $100 \%$ dengan kriteria sangat baik $(\mathrm{AB})$ dan kesenjangan $0 \%$ serta pelaksanaan prinsip Good Governance pada SPM jenis pelayanan Manajemen Berbasis Sekolah dengan skor 100\% memperoleh kriteria baik (B). Hasil dari enam jenis pelayanan serta pelaksanaan prinsip Good Governance dengan kriteria yang diperoleh dapat dilihat dari tabel 1.2.

Tabel 1.2 Skor pencapaian SPM dan Pelaksanaan Prinsip Good Governance

\begin{tabular}{|l|c|c|c|c|}
\hline \multicolumn{1}{|c|}{ Jenis Pelayanan } & $\begin{array}{c}\text { Skor } \\
\text { Pencapaian } \\
\text { SPM (\%) }\end{array}$ & K & $\begin{array}{c}\text { Skor } \\
\text { Pelaksanaan } \\
\text { Good } \\
\text { governance } \\
(\boldsymbol{\%})\end{array}$ & K \\
\hline Sarana dan Prasarana & 94,4 & $\mathrm{~B}$ & 94,2 & $\mathrm{~B}$ \\
\hline Pendidik dan Tenaga Kependidikan & 100 & $\mathrm{AB}$ & 100 & $\mathrm{AB}$ \\
\hline Kurikulum & 88,6 & $\mathrm{~B}$ & 88,8 & $\mathrm{~B}$ \\
\hline Penilaian Pendidikan & 75 & $\mathrm{~B}$ & 75,7 & $\mathrm{~B}$ \\
\hline Penjaminan Mutu Sekolah & 66,7 & $\mathrm{~B}$ & 66,4 & $\mathrm{~B}$ \\
\hline MBS & 100 & $\mathrm{AB}$ & 100 & $\mathrm{AB}$ \\
\hline
\end{tabular}

Sumber: diolah pada 11 Oktober 2015 melalui wawancara dan kuesioner

\section{PEMBAHASAN}

Pencapaian Standar Pelayanan Minimal berdasarkan prinsip Good Governance melalui empat tahap yaitu definisi, instalasi, proses, dan produk pada jenis pelayanan sarana dan prasarana sejalan dengan Peraturan Pemerintah No. 19 tahun 2005 pasal 42 ayat 1 dan 2 tentang standar sarana dan prasarana pendidikan bahwa setiap satuan pendidikan wajib memiliki sarana prasarana yang diperlukan untuk menunjang proses pendidikan.

Jenis pelayanan pendidik dan tenaga kependidikan yaitu guru tetap SD Negeri 4 Kaliaman telah memenuhi jam kerja sesuai dengan SPM. Hal ini selaras dengan Nur (2009: 6) peningkatan kualitas guru menurut model UNESCO adalah kondisi kerja para guru, seperti besarnya kelas, jumlah jam, fasilitas pendukung diperhatikan. Karena jumlah jam mengajar pendidik sangat berpengaruh pada kualitas pendidik.

Standar Pelayanan Minimal mengenai penyusunan RPP berdasarkan silabus pada jenis pelayanan kurikulum tidak selalu dilaksanakan oleh guru sehingga belum tercapai secara maksimal. Hal ini sesuai dengan Nuryani (2014:61) Standar Pelayanan Minimal pada pelayanan kurikulum belum terpenuhi secara maksimal dalam hal penerapan RPP.

Pada jenis pelayanan penilaian, guru sudah mengembangkan instrumen penilaian sesuai KD, melaksanakan penilaian sesuai rencana, dan menggunakan hasil penilaian untuk meningkatkan kemampuan belajar siswa guru sering melakukan penilaian dan melaksanakan 
penilaian sesuai rencana. Pendapat ini sejalan dengan Haryati (2007: 13) penilaian internal merupakan penilaian yang dilakukan dan direncanakan oleh guru pada saat pembelajaran berlangsung.

Jenis pelayanan penjaminan mutu. Mengenai supervisi kepala sekolah. Kepala sekolah belum melakukan supervisi secara berkala. Dengan tidak ada pengawasan oleh kepala sekolah saat guru mengajar menyebabkan guru tidak selalu menyusun RPP berdasarkan silabus. Supervisi dapat membantu guru dalam memperkecil kesenjangan pada indikator penyusunan RPP berdasarkan silabus. Maka pendapat ini selaras dengan Arikunto dan Yuliana (2012:293) supervisi merupakan suatu proses membantu guru dalam memperkecil ketidaksesuaian (kesenjangan) antara tingkah laku pengajar yang nyata dengan tingkah laku mengajar yang ideal. Pada jenis pelayanan penjaminan mutu guru telah menyampaikan laporan hasil evaluasi hasil penilaian peserta didik / rapor terhadap kepala sekolah. Hal ini sejalan dengan Yamin dan Maisah (2010:48) sekolah menetapkan prosedur yang mengatur transparansi sistem evaluasi hasil belajar untuk penilaian formal yang berkelanjutan. Jenis pelayanan penjaminan mutu selanjutnya yaitu Kepala Sekolah telah menyampaikan laporan hasil UAS, UKK, UN kepada orang tua siswa. Hal ini selaras dengan Yamin dan Maisah (2010:48) guru mengembalikan hasil kerja siswa yang telah dinilai dan melaporkan hasil belajar kepada orang tua peserta didik, komite sekolah dan intitusi di atasnya.

Selanjutnya mengenai jenis pelayanan Manajemen Berbasis sekolah, sekolah telah menerapkan prinsip-prinsip MBS yaitu adanya keterlibatan komite, adanya RKT, adanya laporan pertanggungjawaban RKT, dan keterlibatan komite sekolah dalam RKT. Hal ini sejalan dengan Yamin dan Maisah (2010: 58) Kepala Sekolah harus menjabarkan visi dan misi ke dalam target umum, merumuskan tujuan dan target mutu yang akan dicapai, menganalisi tantangan, peluang, kekuatan, kelemahan sekolah, membuat RKS dan RKT untuk pelaksanaan mutu, melibatkan guru dan komite selahkolah dalam pengambilan keputusan penting sekolah, melaksanakan dan merumuskan program supervisi.

\section{SIMPULAN DAN SARAN}

\section{Simpulan}

Berdasarkan hasil penelitian dan pembahasan mengenai pencapaian Standar Pelayanan Minimal berdasarkan prinsip good governance di SD Negeri 4 Kaliaman Jepara diperoleh data sebagai berikut:

Pada tahap definisi sekolah telah mempunyai visi yang sejalan dengan tujuan dibuatnya program Standar Pelayanan Minimal dengan didukung oleh SDM yang memadai dari segi jumlah pendidik dan kualifikasi pendidikan serta sarana dan prasarana yang didukung pemahaman mengenai prinsip Good Governance. Selain itu, tahap instalasi atau 
kelengkapan, sudah dilaksanakan dengan melihat pada harapan dan kegiatan yang dibuat pada RKS serta melihat tantangan yang dihadapi sekolah dengan pelaksanaan prinsip Good Governance yang dilaksanakan disetiap kegiatan pada tiap jenis pelayanan pada SPM. Pada tahap proses, beberapa harapan pada program SPM yang tertuang pada RKS beberapa sudah terwujud dengan pelaksanaan prinsip Good Governance. Pada tahap produk dapat diketahui dari data pencapaian SPM dan pelaksanaan prinsip Good Governance sama-sama memperoleh kategori baik. Secara keseluruhan pencapaian Standar Pelayanan Minimal dari enam jenis pelayanan 87,4 \% memperoleh kriteria baik (B) dan pelaksanaan prinsip Good Governance dengan pelaksanaan 87,5\% dengan kriteria baik (B).

Program masih layak untuk dilanjutkan karena program SPM yang sudah dibuat telah tercapai dan memperoleh kategori baik. Beberapa program belum tercapai disebabkan oleh indikator SPM yang belum dibuat dalam program serta belum dilaksanakan dapat mempengaruhi pencapaian indikator lain seperti pada jenis pelayanan penjaminan mutu pendidikan kepala sekolah belum membuat program supervisi pada RKS sehingga Kepala Sekolah belum melakukan supervisi secara berkala maka mempengarui pencapaian SPM pada kurikulum yaitu penerapan RPP oleh pendidik. Standar Pelayanan Minimal dapat tercapai secara maksimal dengan cara yaitu sekolah harus membuat kebijakan baru dalam program dengan memprioritaskan layanan mana yang dibutuhkan oleh siswa harus diwujudkan pada jenis pelayanan yang pencapaiannya belum maksimal pada jenis pelayanan sarana prasarana, kurikulum, penilaian dan penjaminan mutu pendidikan.

Sehingga dapat diperoleh kesimpulan bahwa pelaksanaan prinsip Good Governance yang dilaksanakan guru dan Kepala Sekolah berpotensi mempengaruhi tinggi rendahnya pencapaian Standar Pelayanan Minimal.

\section{Saran}

Dari hasil penelitian yang telah dilaksanakan mengenai pencapaian Standar Pelayanan Minimal berdasarkan prinsip Good Governance, saran yang diberikan adalah sebagai berikut:

\section{a. Bagi Kepala Sekolah}

Karena beberapa indikator penting pada Standar Pelayanan Minimal belum di buat dalam RKS maka sebaiknya Kepala Sekolah membuat kebijakan program baru mengenai Standar Pelayanan Minimal yang belum tercapai secara maksimal supaya pencapaian Standar Pelayanan Minimal bisa tercapai secara maksimal.

\section{b. Bagi guru}

Karena evaluasi itu penting maka sebaiknya pendidik meningkatkan kualitas kinerja serta melaksanakan kegiatan pembelajaran dengan melaksanakan prinsip-prinsip Good Governance dalam proses pembelajaran sehingga dapat memberikan pelayanan secara minimal untuk siswa demi pencapaian Standar Pelayanan Minimal secara maksimal.

\section{c. Bagi Peneliti Selanjutnya}


Pada waktu penulis melakukan penelitian belum memperkenalkan evaluasi discrepancy pada sekolah maka lebih baik jika peneliti selanjutnya memperkenalkan jenis evaluasi discrepancy, setelah itu baru diteliti maka akan ditemukan hasil yang berbeda.

\section{UCAPAN TERIMAKASIH}

Terimakasih diucapkan kepada Prof. Dr. Slameto, MPd yang telah membimbing baik selama penulisan Tesis maupun selama penulisan artikel ringkasan Tesis ini.

\section{DAFTAR PUSTAKA}

Amtu, O. 2011. Manajemen Pendidikan di Era Otonomi Daerah: Konsep, Strategi dan Implementasi. Bandung: Alfabeta

Arikunto, S., Yuliana, Lia. 2012. Manajemen Pendidikan. Yogyakarta: Aditya Media, Cet-2

Dikdas Bantul. 2014. Evaluasi SPM Dikdas Bantul. Yogyakarta: Dikdas Bantul.

Haryati, M. 2007. Model dan Teknik Penilaian Pada Tingkat Satuan Pendidikan. Jakarta: Gaung Persada Press.

Mulyana, Y. 2009. Peran KepalaSekolah Dasar Dalam Pengembangan Profesionalisme Guru. Jurnal Kependidikan TRIADIK, Volume 12, No. 1.

Nur, H. 2009. Pendidik dan Tenaga Kependidikan. Jurnal MEDTEK, Volume 1, No. 2, Oktober 2009.

Nuryani, K. 2014. Evaluasi Pelaksanaan Standar Pelayanan Minimal Pendidikan Dasar SD Unggulan Muhammadiyah Kretek Kabupaten Bantul Tahun Ajaran 2013/2014.

Peraturan Menteri Pendidikan dan Kebudayaan Nomor 23 tahun 2013 tentang Standar Pelayanan Minimal Pendidikan Dasar di Kabupaten/Kota. Jakarta: Depdikbud

Peraturan Pemerintah No. 19 tahun 2005 tentang Standar Sarana dan Prasarana Pendidikan. Jakarta: Dekdiknas

Permendikbud Nomor 23 tahun 2013 tentang Standar Pelayanan Minimal. Jakarta: Depdikbud

Riduwan. 2011. Belajar Mudah Penelitian untuk Guru-Karyawan dan Peneliti Pemula. Bandung: Alfabeta

Suara Merdeka. 2013. SPM Pendidikan Masih Terkendala. http://www.suaramerdeka.com/v1/index.php/read/cetak/2013/09/23/237676/SPMPendidikan-Masih-Terkendala

Yamin, M. dan Maisah. 2010. Standarisasi Kinerja Guru. Jakarta: Gaung Persada. 